\title{
Investigate the effective Management of Volleyball Thailand League in the perception of volleyball playes
}

\author{
Dr. Watchara Yisunthet, Tanaporn Noosatsung \\ Post Gaduat School of Business Admintration, Kasembundit University, Bangkok
}

\begin{abstract}
The primary purpose of this study is to determine the concepts of team management and perspective of the athletes' on professional Volleyball club Thailand league. The samples were selected from 124 professional by using a check list and rating scale questionnaire as a tool. Statistical application used for data analysis was percentage, mean, standard deviation, $t$-test, One-way Anova, and regression analysis. Findings indicated that most of respondents were females, age 20-29 years old, bachelor degree graduated, average monthly income 15,000-30,000 baht found that the average picture of opinions of professional Volleyball club managing factors were in high level consisting of strategy, professional Volleyball club management, leadership, and control. The test of hypothesis revealed that the personnel different, such as gender, age, level of education, and average income affected professional Volleyball club Thailand league athletes at statistical significant 0.05 level. Also, the factors of management, leadership, vision, compensation, and work environment correlated with athletes' satisfaction of professional Volleyball club Thailand league at statistical significant 0.05 level.

Recommendations from the study were that administrative officers should allow athletes opinions and suggestions regarding team management, allow athlete to evaluate the club management and use this evaluation information to improve and develop the team. Therefore, the information that executive receive should provide the answer for them to improve their managing knowledge skills on professional Volleyball club Thailand league.
\end{abstract}

Keywords: Volleyball, playes, League

\section{Introduction}

Sport is necessary and important in the development of people and nation. The sport is so important that his Majesty the King of Thailand to confer the commands in national sports day "In our sport, the main purpose is to promote strong body, and enable to show positive ability in sport and also for unity which make the life quality better. At the meantime, sports are important in another way which turn people in the nation into practice for health and soul. The ability to live in happy society and wealth to the country as well, especially the international sports will add relationship with another human being from another countries. Therefore, sports are very important to each individual life and life of the cities, if we play with manners, politeness and rules that will be well-known to the other and will promote unity to our nation.” (King Bhumipol Adulyadej, (2552). Cited in Jirasak Pumpoung. (2553: 1)

Sports are all forms of usually competitive physical activity or games which, through casual or organized participation, aim to use, maintain or improve physical ability and skills while providing enjoyment to participants, and in some cases, entertainment for spectators. Usually the contest or game is between two sides, each attempting to exceed the other. Some sports allow a tie game; others provide tiebreaking methods, to ensure one winner and one loser. A number of such two-sided contests may be arranged in a tournament producing a champion. Many sports leagues make an annual champion by 
arranging games in a regular sports season, followed in some cases by playoffs. Hundreds of sports exist, from those between single contestants, through to those with hundreds of simultaneous participants, either in teams or competing as individuals. In certain sports such as racing, many contestants may compete, each against all with one winner.

As from introduction above, researcher are interested in determining the concepts of team management and perspective of the athletes' on professional Volleyball club Thailand league and use the results from the study to prepare a guideline for professional Volleyball club to develop their team for the best.

\section{Purpose of the study}

The primary purpose of this study is to determine the concepts of team management and perspective of the athletes' on professional Volleyball club Thailand league.

\section{Methodology of the Study}

The samples were selected from 124 professional by using a check list and rating scale questionnaire as a tool. Statistical application used for data analysis was percentage, mean, standard deviation, t-test, One-way Anova, and regression analysis.

\section{Results from the Study}

\section{Factors of club management}

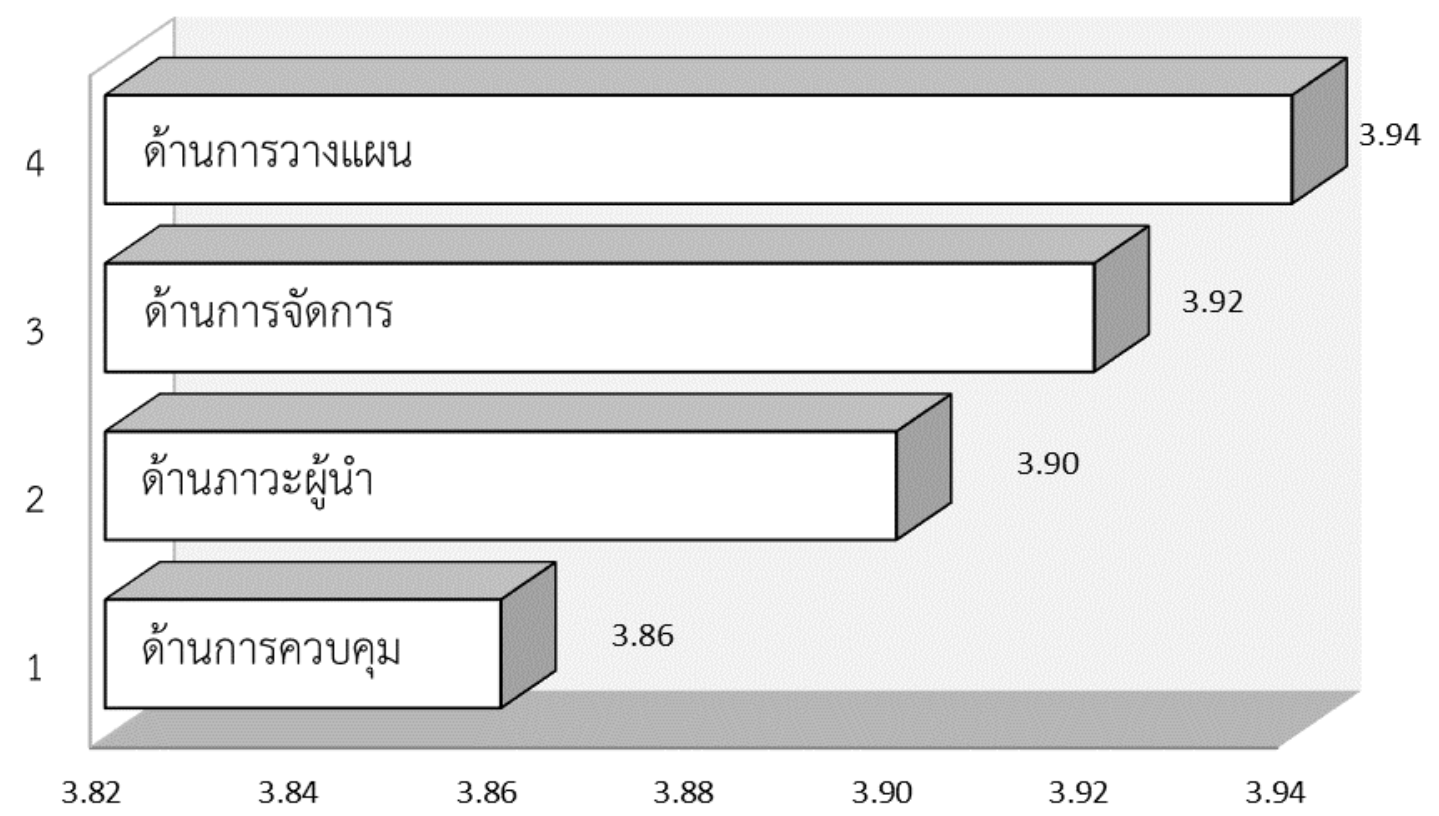

Fig. 1:

Factors of athletes satisfaction regarding of club management revealed that the average picture of opinions were at high level $(\bar{x}=3.91)$ consisted of strategy aspect $(\bar{x}=3.94)$, managing team aspect $(\bar{x}=3.92)$, leadership aspect $(\bar{x}=3.90)$, and management aspect $(\bar{x}=3.86)$, respectively. 
TABLE I: shows the results of athletes satisfaction with their Volleyball team

\begin{tabular}{|c|c|c|c|c|c|c|}
\hline Concepts of team management & $\mathbf{B}$ & $\begin{array}{l}\text { Std. } \\
\text { error }\end{array}$ & Beta & $\mathbf{t}$ & Sig. & Results \\
\hline (Constant) & .920 & .358 & & 2.567 & & Not relate \\
\hline \multicolumn{7}{|c|}{ Strategy aspect } \\
\hline Games practice schedule & .040 & .083 & .044 & .477 & .634 & Not relate \\
\hline Prepare to recruit athletes & .106 & .110 & .098 & .966 & .335 & Not relate \\
\hline Personnel development & -.026 & .085 & -.029 & -.310 & .757 & Not relate \\
\hline Sport event schedule yearly & -.031 & .093 & -.036 & -.333 & .740 & Not relate \\
\hline \multicolumn{7}{|c|}{ Managing aspect } \\
\hline Inform game results routinely & .015 & .096 & .018 & .158 & .875 & Not relate \\
\hline Inform athletes the changes & -.013 & .100 & -.014 & -.131 & .896 & Not relate \\
\hline Suitable coach for athletes & -.010 & .095 & -.011 & -.107 & .915 & Not relate \\
\hline Coach with clearly duty & .120 & .118 & .131 & 1.016 & .311 & Not relate \\
\hline Routine communication to athletes & -.044 & .101 & -.048 & -.435 & .664 & Not relate \\
\hline \multicolumn{7}{|c|}{ Leadership aspect } \\
\hline Administrative officer have clear vision & .170 & .092 & .201 & 1.844 & $.047 *$ & Related \\
\hline Managing team have games knowledge & -.168 & .117 & -.174 & -1.432 & .154 & Not relate \\
\hline $\begin{array}{l}\text { Managers have close relationship with } \\
\text { athletes }\end{array}$ & .081 & .093 & .086 & .871 & .385 & Not relate \\
\hline Managers give guidance to athletes & .048 & .099 & .054 & .483 & .630 & Not relate \\
\hline $\begin{array}{l}\text { Administrative officers have source of } \\
\text { fund }\end{array}$ & .233 & .088 & .277 & 2.642 & $.009^{*}$ & Related \\
\hline \multicolumn{7}{|c|}{ Managing the team } \\
\hline Administrative officers plan and execute & -.045 & .099 & -.048 & -.454 & .651 & Not relate \\
\hline Managers manage athletes with efficiency & .037 & .102 & .039 & .366 & .715 & Not relate \\
\hline Managers manage funds with efficiency & -.002 & .105 & -.002 & -.022 & .982 & Not relate \\
\hline Managers manage work environment & .254 & .115 & .262 & 2.209 & $.029 *$ & Related \\
\hline
\end{tabular}

$*$ Statistical significant $<0.05$

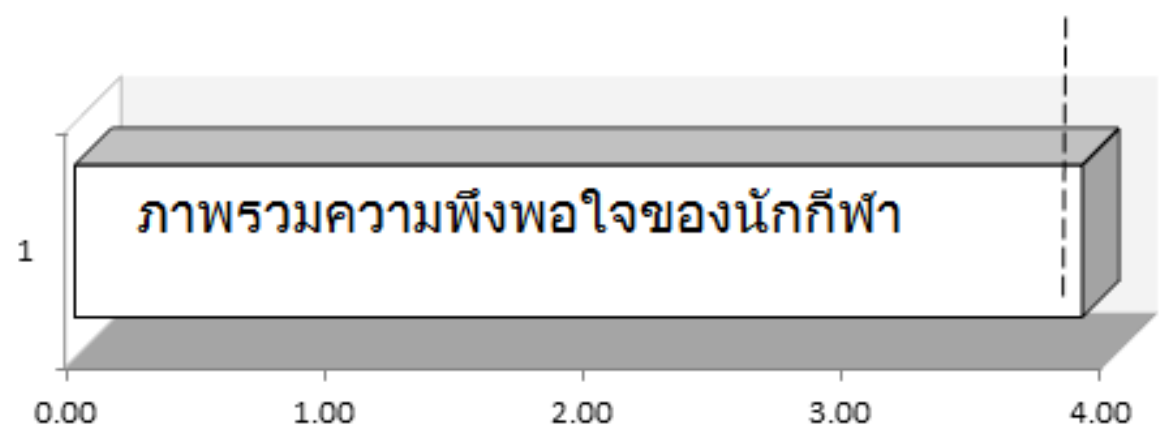

$$
\begin{aligned}
& \text { Average value } \\
& (\bar{x}=3.89)
\end{aligned}
$$


Shows the results of athletes' satisfaction on their professional Volleyball club Thailand league. From study revealed that athletes' satisfaction on professional Volleyball club Thailand league with average picture of the opinions were at high level $(\bar{x}=3.89)$.

\section{Summary of study results}

The purpose of this study was to determine the concepts of team management and perspective of the athletes' on professional Volleyball club Thailand league. The samples were selected from 124 professional by using a check list and rating scale questionnaire as a tool. Statistical application used for data analysis was percentage, mean, standard deviation, t-test, One-way Anova, and regression analysis.

Factors of personal indicated that most of respondents were females, age 20-29 years old, bachelor degree graduated, average monthly income 15,000-30,000 baht

Factors of the concepts of team management and perspective of the athletes' on professional Volleyball club Thailand league revealed that the average picture of the opinion were in high level as details follows:

Strategy aspect with average picture of the opinions were in high level, for example the Volleyball club managers already prepared for the next games, recruited appropriate athletes, human resource development, games planning events clearly every year, prepared for coaching schedules.

Managing aspect with the average picture of the opinions were in high level, such as administrative officers inform the athletes when Volleyball game regulation changed, share the duties and roles of the instructors clearly, planned coaching team with their duty that appropriate to athletes, there are communication between managers and athletes regularly, announced the results to all games to athletes.

Leadership aspect with the average picture of the opinions were in high level, such as administrative officers have closed relationship with athletes, the Committee has participated in the activities of athletes closely and regularly, raised funds to spend on competition and compensation for all expenses, board provided consulting guidance, guidelines, as well as possible solutions to athletes, and executives are clear and visionary.

Team managing aspect with the average picture of the opinions were in high level, such as the executive overseeing the athletes until the end of games, managing club resources with efficiency, well maintain work environment to be ready for the future operations.

\section{References}

[1] Ministry of Tourism and Sports. Searched from http://www.mots.go.th. 2559

[2] Kanjana Arunsukruje. (2546). Cooperative members satisfaction on Agricultural cooperative of Operational of Chaiprakarn Co., Ltd., Chaiprakarn District, Chiengmai Province, Chiengmai University.

[3] Kulya Vanichbuncha. Research methodology. Thammasarn printing, Bangkok.

[4] Research Committee of Ramkamhaeng University. (2554). Searched from http://www.nst.ru.ac.th /index.php?option=com

[5] Jirasak Pumduang. (2553). The desirable characteristics of the referee for $37^{\text {th }}$ University competition games of Volleyball. Thesis, Ramkamhaeng University.

[6] Thongchai Santivong. (2523). Organization and management. $4^{\text {th }}$ edition, Thaiwatana Panich Printing, Bangkok.

[7] Nonchai Santibuth. (2550). Model of professional soccer development of Thailand. Thesis, Chulalongkorn University.

[8] Pranee Bunkiang. (2555). Managing of Professional Volleyball association of Thailand. Thesis, Chiengmai University.

[9] Thailand Sports Development Plan. (2550-2554). $4^{\text {th }}$ edition, search from http://ps.sat.or.th/webPage.aspx?subid=0\&webpageid=2.

[10] Rapeepat Duanpensri. (2553). Conditions, problems, and development guideline of managing Professional soccer club participating in Thailand Premier League competition, 2008. Thesis, Sports Science education, Burapha University.

[11] Siriwan Saerirat \& Associate. (2545). Principle of Organization Management. Diamond in Business World printing, Bangkok. 
[12] Thailand Volleyball Association. History of Thailand Volleyball Association, searched from http://www.volleyball.or.th/th-th/tva/history.

[13] Sakorn Suksrivong. (2550). Management from executive perspective. $3^{\text {rd }}$ edition, GP cyber Printing, Bangkok.

[14] Suratvadi Rachkulchai. (2543). Strategy and management. $2^{\text {nd }}$ edition, Chamchuri printing, Bangkok.

[15] Somyos Navikarn, (2544). Managing for excellence. $2^{\text {nd }}$ edition, Bunnakit printing, Bangkok

[16] Soitrakul Uttamana. (2545). Organization behavior: Theory and apply, $3^{\text {rd }}$ edition, Thammasart University, Bangkok.

[17] Bridges and Roquemore. Management for Athletic Sport Administration: theory and practice 4th. edition. ESM Books. (2001). 